\title{
Vitamin B12 Serum Levels of Six to Nine-month- old Infants According to Feeding Practices
}

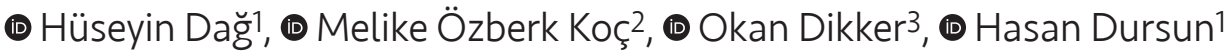 \\ 1University of Health Sciences Turkey, İstanbul Okmeydanı Training and Research Hospital, Clinic of Pediatrics, İstanbul, Turkey \\ 2Bakırköy Children's Health and Diseases Clinic, Department of Pediatricians, İstanbul, Turkey \\ 3University of Health Sciences Turkey, İstanbul Okmeydanı Training and Research Hospital, Clinic of Medical Biochemistry, İstanbul, Turkey
}

\begin{abstract}
Aim: Vitamin B12 is naturally obtained from animal-derived foods and is important for the development and wellbeing of babies. Vitamin B12 deficiency is a general health concern in developing countries. This study aimed to investigate the effects of different feeding practices on vitamin B12 levels and hemogram parameters in infants aged 6-9 months.

Materials and Methods: A total of 120 infants (61 boys, 59 girls) aged 6-9 months were retrospectively evaluated. These babies were assigned to three groups according to feeding practices: 1) only breast milk, 2) breast milk and formula, and 3) only formula in addition to complementary foods. Laboratory data (vitamin B12, hemoglobin, hematocrit, mean corpuscular volume, white blood cell count, and absolute neutrophil count) of the patients were retrospectively compared.

Results: The mean and median age of the patients was 6.6 \pm 1.1 months. The vitamin B12 levels in babies that only received formula were statistically significantly higher than those in babies taking only breast milk or taking both breast milk and formula $(p<0.05)$. Furthermore, vitamin B12 levels were significantly lower in babies receiving only breast milk than in those receiving both formula and breast milk ( $p<0.001)$.

Conclusion: This study showed that vitamin B12 levels were lower in babies that only received breast milk compared to those in babies receiving formula. The babies that were receiving formula only had the highest levels of vitamin B12. This study determined that breast milk alone was not sufficient to maintain normal levels of vitamin B12 in 6 to 9-month-old babies in the region. Therefore, both mothers and babies should be provided with the necessary support in terms of vitamin B12 levels, and prophylaxis should be discussed from the viewpoint of preventive healthcare services.
\end{abstract}

Keywords: Child, breast milk, formula, vitamin B12

\section{Introduction}

The most significant role of vitamin B12 is its function in DNA synthesis, which is required for cell division and proliferation. Vitamin B12 is water-soluble and synthesized mainly by microorganisms. Humans cannot synthesize vitamin B12. Vitamin B12 is obtained from cobalamin in foods, and especially in animal-derived foods. Dietary deficiency of this vitamin is rare for those who have normal eating habits, as the amount of vitamin B12 is sufficient in most animalobtained foods. However, vitamin B12 inadequacy is seen in those with a low dietary intake of vitamin B12 (1).

Vitamin B12 is a significant factor for the process of child development. Vitamin B12 deficiency can cause neurological disorders and hematologic changes, in addition 
to developmental delays and regressions (1). Vitamin B12 fortified foods and supplements, in addition to animalderived foods, can be consumed in cases of deficiency (2). Vitamin B12 inadequacy is prevalent in those on strict vegetarian or vegan regimes as well as in individuals who live in developing countries (3-6).

Breast milk is the main source of micronutrients needed by a newborn (7), and babies who are only fed with breast milk receive nearly $0.25 \mu \mathrm{g}$ vitamin $\mathrm{B} 12$ from a healthy mother within the first 6 months (4). The vitamin B12 level of babies is associated with the vitamin B12 level of their mothers (8). Previous studies have shown that babies receiving breast milk alone had notably lower serum vitamin $\mathrm{B} 12$ rates in comparison to those babies receiving formula $(9,10)$.

Delayed diagnosis and treatment during childhood, in spite of the low cost of this treatment, may entail irreversible neurological damage, in addition to severe anemia. Therefore, patients presenting to an outpatient clinic should be examined for vitamin B12 inadequacy. Anemia within the first 2 years of life can occur due to a vitamin B12 deficiency in breastmilk, especially in developing countries, and manifests with neurodevelopmental delay $(11,12)$.

This research aimed at investigating the effectiveness of varied feeding practices on vitamin B12 serum levels and hemogram parameters in 6 to 9 -month-old infants.

\section{Materials and Methods}

The Clinical Trials Ethics Committee of Okmeydanı Training and Research Hospital approved this study as per the approval number:1079, date: December 18 ${ }^{\text {th }}, 2018$. Consent forms were filled out by all participants. The study groups consisted of 120 babies aged 6-9 months, consisting of 61 males and 59 females who did not have any medical problems and were brought to the pediatric outpatient clinics of Okmeydanı Training and Research Hospital between January 2018 and November 2018 for routine checkup and immunization follow-up. Data on feeding history and multivitamin use were obtained for all infants. Babies who were premature, had a low birth weight, had any metabolic or chronic disease, or were hospitalized for any disease were excluded from this study. Patients who had incomplete files, or those who did not have data concerning B12 levels or complete blood count data, or those with an indeterminable feeding history were not included in this study.
The infants were divided into three groups according to their feeding practices: 1) only breast milk, 2) breast milk and formula, and 3) only formula in addition to complementary foods. In this study, 77 babies received only breast milk, 19 babies received both breast milk and formula, and 24 babies received formula only. In addition, all babies were receiving complementary foods according to the statements of their families. However, objective data on the amount of complementary foods given to the baby could not be obtained. Laboratory datum [vitamin B12, hemoglobin $(\mathrm{Hb})$, hematocrit (Hct), mean corpuscular volume (MCV), white blood cell count (WBC), and absolute neutrophil count (ANC)] of the patients were retrospectively evaluated between the groups. Vitamin B12 levels were assayed using the chemiluminescent immunoassay with a Roche Cobas Integra 400 Plus analyzer. Values lower than 250 pg/mL were considered low. Hemogram parameters were assayed with a Mindray BC-6800 hemogram device.

\section{Statistical Analysis}

Data were analyzed using the SPSS 20.0 for Windows package software (IBM). Continuous variable data with a normal distribution are given as mean \pm standard deviation, and data with a non-normal distribution are given as median and range. Data with a normal distribution was analyzed using a histogram and Kolmogorov-Smirnov test. The statistical differences between non-normal data were analyzed using the Mann-Whitney $U$ test, while the differences between more than two groups were analyzed using the Kruskal-Wallis test. The statistical differences between two categorical datasets were analyzed using the chi-square test. Categorical data are stated numerically with percentage. $\mathrm{P}<0.05$ was acknowledged as statistically meaningful.

\section{Results}

The mean and median age of the patients was $6.6 \pm 1.1$ months; $50.8 \%(n=61)$ of the patients were male and $49.1 \%$ $(n=59)$ of the patients were female. Vitamin B12 levels in those infants that only received formula were statistically notably higher than those in infants receiving only breast milk or both breast milk and formula $(p<0.05)$. Vitamin B12 levels were significantly lower in infants receiving only breast milk than in those receiving formula in addition to breast milk $(p<0.05)$. There was no statistically notable difference between the groups in terms of $\mathrm{Hb}, \mathrm{Hct}, \mathrm{MCV}$, WBC, and ANC levels (Table 1). 
Vitamin B12 deficiency was mainly seen in babies receiving only breast milk. None of the babies receiving only formula had vitamin B12 deficiency (Table 2).

The mean baby weight, gender, type of birth (normal birth or cesarean section) and gestational weeks of the three groups were found to be statistically similar (Table 3).

\section{Discussion}

Vitamin B12 deficiency is a health worry generally encountered in developing countries (5). Vitamin B12 is critical for development during the fetal, neonatal, and infancy periods.

Therefore, vitamin B12 deficiency can cause numerous diseases, especially developmental and neurological disorders $(13,14)$. It is important for a mother to consume foods that are rich in vitamin B12 throughout the lactation period (15). It is recommended to breastfeed babies for more than 6 months, and breast milk is a natural source of vitamin B12 for the baby. However, some studies have shown that restrictive vegetarian and vegan diets resulted in lower levels of vitamin B12 in the mother and therefore led to vitamin B12 deficiency in babies (4,15-18). Vitamin B12

Table I. Biochemical data of the groups according to feeding practices

\begin{tabular}{|l|l|l|l|l|}
\hline Parameters & $\begin{array}{l}\text { Babies } \\
\text { receiving } \\
\text { breast milk } \\
\text { only (n=77) } \\
\text { (mean } \pm \text { SD) }\end{array}$ & $\begin{array}{l}\text { Babies } \\
\text { receiving } \\
\text { breast milk } \\
\text { + formula } \\
\text { (n=19) } \\
\text { (mean } \pm \text { SD) }\end{array}$ & $\begin{array}{l}\text { Babies } \\
\text { receiving } \\
\text { formula only } \\
\text { (n=24) } \\
\text { (mean } \pm \text { SD) }\end{array}$ & $\mathbf{p}$ \\
\hline $\begin{array}{l}\text { Vitamin B12 } \\
\text { (pg/mL) }\end{array}$ & $228.8 \pm 155.5$ & $359.5 \pm 192.9$ & $618.5 \pm 248.2$ & 0.002 \\
\hline Hb (g/dL) & $11.5 \pm 1.0$ & $11.6 \pm 0.8$ & $11.9 \pm 1.0$ & 0.404 \\
\hline Hct (\%) & $33.8 \pm 3.2$ & $33.0 \pm 2.5$ & $34.1 \pm 3.0$ & 0.295 \\
\hline MCV (fL) & $90.6 \pm 106.5$ & $73.4 \pm 3.3$ & $74.9 \pm 4.3$ & 0.380 \\
\hline WBC (mm ) & $9.549 \pm 2.544$ & $10.248 \pm 2.568$ & $8.655 \pm 1.541$ & 0.194 \\
\hline ANC (mm ${ }^{3}$ ) & $2.224 \pm 1.465$ & $1.762 \pm 714$ & $1.989 \pm 714$ & 0.400 \\
\hline $\begin{array}{l}\text { *, Kruskal-Wallis test, ANC: Absolute neutrophil count, MCV: Mean corpuscular } \\
\text { volume, RBC: Red blood cell, WBC: White blood cell, SD: Standard deviation, Hb: } \\
\text { Hemoglobin, Hct: Hematocrit }\end{array}$ \\
\hline
\end{tabular}

deficiency is not uncommon in babies receiving only breast milk (4,17-21). Studies have shown that babies who were fed formula had increased vitamin B12 levels compared to those that were breast fed $(9,10)$.

In this study, the effects of varied feeding implementations on vitamin B12 levels in the bloodstream of babies who were brought to our hospital were investigated. Similar to other studies, this current study revealed that vitamin B12 levels were lower in infants receiving only breast milk compared to those receiving formula in addition to breast milk as well as those receiving only formula. It was also observed that those babies who were only receiving formula had much higher levels of vitamin B12. According to these results, it was apparent that vitamin B12 levels differed according to feeding practices. It is therefore important to consume formulas fortified with vitamin B12 to prevent vitamin B12 deficiency.

Vitamin B12 insufficiency in mothers is the leading reason of vitamin B12 deficiency in babies during infancy. When babies are only fed breast milk, they can have severe vitamin B12 deficiency if their mothers also have vitamin B12 deficiency. $(22,23)$. In a study conducted in Istanbul and Izmit, Ackurt reported that $48 \%$ of women in the early pregnancy period (13-17 weeks), $80 \%$ of women in the late pregnancy period (28-32 weeks), and 60\% of women in the postpartum period had vitamin B12 deficiency. In addition, the delayed or non-introduction of complementary feeding or feeding babies with cow's milk as the primary food source contributed to vitamin B12 insufficiency in infants (24). In

Table II. Evaluation of vitamin B12 levels according to the reference interval in different feeding practices

\begin{tabular}{|l|l|l|l|}
\hline & $\begin{array}{l}\text { Babies } \\
\text { receiving } \\
\text { only breast } \\
\text { milk (n=77) }\end{array}$ & $\begin{array}{l}\text { Babies } \\
\text { receiving } \\
\text { breast milk } \\
\text { and formula } \\
\text { (n=19) }\end{array}$ & $\begin{array}{l}\text { Babies } \\
\text { receiving } \\
\text { only } \\
\text { formula } \\
\text { (n=24) }\end{array}$ \\
\hline $\begin{array}{l}\text { Vitamin B12 below } \\
\text { the reference } \\
\text { interval }\end{array}$ & $37(48.1 \%)$ & $3(15.8 \%)$ & $0-0$ \\
\hline $\begin{array}{l}\text { Vitamin B12 within } \\
\text { the reference } \\
\text { interval }\end{array}$ & $40(51.9 \%)$ & $16(84.2 \%)$ & $24(100 \%)$ \\
\hline
\end{tabular}

Table III. Demographic features of babies

\begin{tabular}{|l|l|l|l|l|}
\hline & $\begin{array}{l}\text { Babies receiving } \\
\text { breast milk (n=77) }\end{array}$ & $\begin{array}{l}\text { Babies receiving breast } \\
\text { milk + formula (n=19) }\end{array}$ & $\begin{array}{l}\text { Babies receiving } \\
\text { formula only (n=24) }\end{array}$ & $\mathbf{p}$ \\
\hline Baby weight (gram) & $3,520.2 \pm 199.5$ & $3.466 \pm 121.2$ & $3.320 \pm 124.2$ & $0=0.124$ \\
\hline Baby gender (male/female) & $35 / 42$ & $10 / 9$ & $13 / 11$ & $0=0.130$ \\
\hline Delivery method (normal birth/cesarean section) & $45 / 32$ & $13 / 6$ & $17 / 7$ & $0=0.109$ \\
\hline Gestational week (week) & $39.1 \pm 0.4$ & $39.3 \pm 0.8$ & $38.9 \pm 0.7$ & $0=0.095$ \\
\hline
\end{tabular}


another study conducted in Sivas, Demirel et al. (25) stated that the incidence of vitamin B12 insufficiency during the third trimester was $66.7 \%$ in healthy pregnant women.

In a study by Koç et al. (26), 39.8\% of babies who were healthy according to their families had a vitamin B12 deficiency, and $75 \%$ of the mothers of those babies with vitamin B12 deficiency also had vitamin B12 insufficiency. Monagle et al. (27) found infantile megaloblastic anemia in 19 children under the age of 1 in their clinic, and reported that vitamin B12 insufficiency in $6(30 \%)$ children was secondary to the vitamin B12 insufficiency in their mothers, and that these 6 children were only receiving breast milk. In another study, Minet et al. (28) demonstrated that healthy infants who were receiving breast milk had lower vitamin B12 levels than those who were receiving formula.

This current study's findings are similar to the results of previous studies. It has been determined that, despite complementary feeding, breast milk alone was not adequate to sustain normal levels of vitamin B12 in 6 to 9-month-old infants in this region. Vitamin B12 levels, which can lead to negative outcomes in cases of deficiency, should be measured in infants $(22,28)$. Vitamin B12 levels should also be assessed in mothers, and those with low levels of vitamin B12 should be provided with vitamin supplement in order to increase the vitamin B12 level in their breast milk. Accordingly, a vitamin B12 test and complete blood count should be performed when an infant is brought to an outpatient clinic. In this study, 3 babies had a vitamin B12 deficiency even though they were receiving formula in addition to breast milk. Consequently, formula intake cannot completely rule out vitamin B12 deficiency, since infants taking formula in addition to breast milk also had a vitamin B12 deficiency.

When clinical signs suggest vitamin B12 deficiency in a child, fasting plasma homocysteine levels should be investigated even if serum vitamin $\mathrm{B} 12$ level and $M C V$ results are normal. It has been reported that testing only for vitamin B12 levels could lead to a misdiagnosis in $10-26 \%$ of patients. Accuracy can be increased to $99.8 \%$ when methyl malonic acid and homocysteine tests are carried out (29). Accurate diagnosis is of the utmost importance in these patients in order to administer vitamin B12 in addition to treatment to the infants receiving breast milk. Homocysteine levels were not measured in this study as none of the patients had neurodevelopmental disorders, according to their records. Moreover, we suggest that standard algorithms concerning an approach to vitamin B12 deficiency in children can be created as the number of studies on this field increases.
Previous studies have shown that vitamin B12 insufficiency can be caused by strict vegetarian diets or pernicious anemia for $90 \%$ of infants $(27,30)$. On the other hand, determinants such as poverty or low socioeconomic status, incorrect feeding habits, and an increased use of vitamin B12 due to a high number of pregnancies also have an impact on the high percentage of vitamin B12 deficiency in babies and their mothers in underdeveloped and developing countries $(31,32)$. It is also apparent that the risk of developing vitamin B12 deficiency increases with lower economic status and a higher number of pregnancies. In the current study, none of the babies receiving formula had a vitamin B12 deficiency. Therefore, infants should receive a sufficient amount of complementary foods rich in vitamin B12. Accordingly, it is important to consider and provide early treatment for vitamin B12 deficiency in breastfeeding mothers and their infants with a low intake of animal-derived foods, especially in regions with low socioeconomic status, in addition to a vegetarian diet.

Of the hematologic findings for vitamin B12 deficiency, increased MCV characteristically develops before anemia, and the clinical signs are observed at a later time. This study found that there was no statistically major variation between the groups with respect to MCV levels in healthy infants who had different feeding practices. However, the MCV levels in infants that only received breast milk were increased compared to those in the other groups.

It was observed that vitamin B12 levels were lower in infants taking only breast milk than in those taking formula, and that babies who were only taking formula had the highest levels of vitamin B12. This research confirmed that breast milk alone was not adequate to maintain normal levels of vitamin B12 in 6 to 9-month-old infants in the region. Accordingly, vitamin B12 levels should be checked during pregnancy and in case of deficiency, a suitable replacement therapy should be provided for pregnant women in a manner to encompass the postpartum period in order to protect the baby from the dramatic outcomes of vitamin B12 insufficiency. Vitamin B12 levels must be tested in addition to a complete blood count in routine screening of children. Formula should be recommended for babies found to have vitamin B12 deficiency to supplement insufficient breast milk from their mothers. Replacements should be administered if there is a vitamin B12 deficiency despite sufficient breast milk. In addition, routine B12 prophylaxis and dosages in infants should be discussed as a part of preventive medicine practices in developing countries. 
Acknowledgments: This research did not receive any specific grants from any funding agency in the public, commercial, or not-for-profit sector.

\section{Ethics}

Ethics Committee Approval: The Clinical Trials Ethics Committee of Okmeydanı Training and Research Hospital approved this study as per the approval number: 1079, date: December 18th, 2018.

Informed Consent: Consent forms were filled out by all participants.

Peer-review: Externally peer-reviewed.

\section{Authorship Contributions}

Concept: H.D., M.Ö.K., Design: M.Ö.K., O.D., H.D., Data Collection or Processing: H.D., Analysis or Interpretation: O.D., Ha.D., Literature Search: Ha.D., Writing: H.D.

Conflict of Interest: No conflict of interest was declared by the authors.

Financial Disclosure: The authors declared that this study received no financial support.

\section{References}

1. Monsen AL, Refsum H, Markestad T, Ueland PM. Cobalamin status and its biochemical markers methylmalonic acid and homocysteine in different age groups from 4 days to 19 years. Clin Chem 2003;49:2067-75.

2. Allen LH. How common is vitamin B-12 deficiency? Am / Clin Nutr 2009;89:693S-6S.

3. Pawlak R, Parrott S), Raj S, Cullum-Dugan D, Lucus D. How prevalent is vitamin $B(12)$ deficiency among vegetarians? Nutr Rev 2013;71:110-7.

4. Dror DK, Allen LH. Effect of vitamin B12 deficiency on neurodevelopment in infants: current knowledge and possible mechanisms. Nutr Rev 2008;66:250-5.

5. Ng'eno BN, Perrine CG, Whitehead RD, et al. High Prevalence of Vitamin B12 Deficiency and No Folate Deficiency in Young Children in Nepal. Nutrients 2017;9. pii: E72.

6. Jones KM, Ramirez-Zea M, Zuleta C, Allen LH. Prevalent vitamin B-12 deficiency in twelve-month-old Guatemalan infants is predicted by maternal B-12 deficiency and infant diet. I Nutr 2007;137:1307-13

7. Gernand AD, Schulze KJ, Stewart CP, West KP Jr, Christian $P$. Micronutrient deficiencies in pregnancy worldwide: health effects and prevention. Nat Rev Endocrinol 2016;12:274-89.

8. Chebaya P, Karakochuk CD, March KM, et al. Correlations between Maternal, Breast Milk, and Infant Vitamin B12 Concentrations among Mother-Infant Dyads in Vancouver Canada and Prey Veng, Cambodia: An Exploratory Analysis. Nutrients 2017;9. pii: E270.

9. Karademir F, Suleymanoglu S, Ersen A, et al. Vitamin B12, folate, homocysteine and urinary methylmalonic acid levels in infants. J Int Med Res. 2007;35:384-8.
10. Specker BL, Brazerol W, Ho ML, Norman EJ. Urinary methylmalonic acid excretion in infants fed formula or human milk. Am / Clin Nutr 1990;51:209-11.

11. Roschitz B, Plecko B, Huemer M, Biebl A, Foerster H, Sperl W. Nutritional infantile vitamin B12 deficiency: pathobiochemical considerations in seven patients. Arch Dis Child Fetal Neonatal Ed 2005;90:F281-2.

12. Brocadello F, Levedianos G, Piccione F, Manara R, Pesenti FF. Irreversible subacute sclerotic combined degeneration of the spinal cord in a vegan subject. Nutrition 2007;23:622-4.

13. Ludwig ML, Matthews RG. Structure-based perspectives on B12dependent enzymes. Annu Rev Biochem 1997;66:269-313.

14. Kamei $\mathrm{M}$, Ito $\mathrm{Y}$, Ando $\mathrm{N}$, et al. Brain atrophy caused by vitamin B12-deficient anemia in an infant. I Pediatr Hematol Oncol 2011;33:556-8.

15. Van Winckel M, Vande Velde S, De Bruyne R, Van Biervliet S. Clinical practice: vegetarian infant and child nutrition. Eur I Pediatr 2011;170:1489-94.

16. Breastfeeding and the use of human milk. American Academy of Pediatrics. Work Group on Breastfeeding. Pediatrics 1997;100:1035-9.

17. Carmel R. Current concepts in cobalamin deficiency. Annu Rev Med 2000;51:357-75.

18. Sklar R. Nutritional vitamin B12 deficiency in a breast-fed infant of a vegan-diet mother. Clin Pediatr (Phila) 1986;25:219-21.

19. Guez S, Chiarelli G, Menni F, Salera S, Principi N, Esposito S. Severe vitamin B12 deficiency in an exclusively breastfed 5-month-old Italian infant born to a mother receiving multivitamin supplementation during pregnancy. BMC Pediatr 2012;12:85.

20. Institute of Medicine Standing Committee on the Scientific Evaluation of Dietary Reference I, its Panel on Folate OBV, Choline: The National Academies Collection: Reports funded by National Institutes of Health. In Dietary Reference Intakes for Thiamin, Riboflavin, Niacin, Vitamin B6, Folate, Vitamin B12, Pantothenic Acid, Biotin, and Choline. Washington (DC): National Academies Press (US) National Academy of Sciences.; 1998.

21. Akcaboy M, Malbora B, Zorlu P, Altinel E, Oguz MM, Senel S. Vitamin B12 Deficiency in Infants. Indian I Pediatr 2015;82:61924.

22. Watkins D, Whiteheat VM, Rosenblatt DS: Megaloblastic anemia. In: Orkin SH, Fisher DE, Look AT, Lux SE, Ginsburg D, Nathan DC (eds). Nathan and Oski's Hematology of Infancy and Chilhood. (7th ed), Philadelphia: Saunders Elsevier, 2009:469-521.

23. Davis JR, Goldenring J, Lubin BH. Nutritional vitamin B12 deficiency in infants. Am J Dis Child 1981;135:566-7.

24. Ackurt F, Wetherilt $H$, Loker $M$, Hacibekiroglu M. Biochemical assessment of nutritional status in pre- and post-natal Turkish women and outcome of pregnancy. Eur J Clin Nutr 1995;49:61322.

25. Demirel Y, Erden Ö, Duran B, Kula A, Özdemir L, Çetin M. Sivas ilinde preeklamptik ve sağlıklı gebelerin serum B12 vitamini ve folik asit düzeylerinin karşılaştırılması. Türk Aile Hek Derg 2005;9:57-60.

26. Koç A, Ertaş T, Tatlı MM, Koçylğit A. Şanlıurfa'da Altı-On iki Aylık Çocuklarda B12 Vitamini Eksikliğinin Sıklığı, Çocukların 
Beslenme Durumu ve Annelerindeki Eksiklik ile illişkisi. Türk Çocuk Hematoloji Dergisi 2011;5:11-9.

27. Monagle PT, Tauro G. Infantile megaloblastosis secondary to maternal vitamin B12 deficiency. Clin Lab Hematol 1997;19:23-5.

28. Minet JC, Bisse E, Aebischer CP, Beil. A, Wieland H, Lütschg J. Assesment of vitamin B12, folate and vitamin B-6 status and relation to sulfur amino acid metabolism in neonates. Am J Clin Nutr 2000;72:751-7.

29. Savage DG, Lindenbaum J, Stabler SP. Sensitivity of serum methylmalonic acid and total homocysteine derterminations for diagnosing cobalamin and folate deficiencies. Am I Med 1994;96:239-46.

30. Kühne T, Bubl R. Baumgartner. Maternal vegan diet causing a serious infantile neurological disorder due to vitamin B12 deficiency. Eur J Pediatr 1991;150:205-8.

31. Stabler SP, Allen RH. Vitamin B12 deficiency as a worldwide problem. Annu. Rev. Nutr 2004;24:299-326.

32. Maktouf $\mathrm{C}$, Bchir A, Louzir $\mathrm{H}$, et al. Megaloblastic anemia in Africa. Haematologica 2006;91:990-1. 